\title{
Characterization of primary human mammary epithelial cells isolated and propagated by conditional reprogrammed cell culture
}

\author{
Liting Jin ${ }^{1,2, *}$, Ying Qu ${ }^{2, *}$, Liliana J. Gomez ${ }^{2}$, Stacey Chung ${ }^{2}$, Bingchen Han ${ }^{2}$, Bowen \\ $\mathrm{Gao}^{2}$, Yong $\mathrm{Yue}^{3}$, Yiping Gong ${ }^{1}$, Xuefeng Liu ${ }^{4}$, Farin Amersi' ${ }^{2}$, Catherine Dang ${ }^{2}$, \\ Armando E. Giuliano ${ }^{2}$ and Xiaojiang Cui ${ }^{2}$ \\ ${ }^{1}$ Department of Breast Surgery, Hubei Cancer Hospital, Wuhan, 430079, China \\ ${ }^{2}$ Department of Surgery, Samuel Oschin Comprehensive Cancer Institute, Cedars-Sinai Medical Center, Los Angeles, CA 90048, USA \\ ${ }^{3}$ Department of Radiation, Samuel Oschin Comprehensive Cancer Institute, Cedars-Sinai Medical Center, Los Angeles, CA 90048, USA \\ ${ }^{4}$ Department of Pathology, Lombardi Comprehensive Cancer Center, Georgetown University, Washington, DC 20057, USA \\ *These authors contributed equally to the work \\ Correspondence to: Xiaojiang Cui, email: Xiaojiang.Cui@cshs.org
}

Keywords: conditional reprogramming; estrogen receptor; mammary epithelial cells; luminal cells; myoepithelial cells

Received: April 07, $2017 \quad$ Accepted: October 30, $2017 \quad$ Published: December 22, 2017

Copyright: Jin et al. This is an open-access article distributed under the terms of the Creative Commons Attribution License 3.0 (CC BY 3.0), which permits unrestricted use, distribution, and reproduction in any medium, provided the original author and source are credited.

\section{ABSTRACT}

Purpose: Conditional reprogramming methods allow for the inexhaustible in vitro proliferation of primary epithelial cells from human tissue specimens. This methodology has the potential to enhance the utility of primary cell culture as a model for mammary gland research. However, few studies have systematically characterized this method in generating in vitro normal human mammary epithelial cell models.

Results: We show that cells derived from fresh normal breast tissues can be propagated and exhibit heterogeneous morphologic features. The cultures are composed of CK18, desmoglein 3, and CK19-positive luminal cells and vimentin, p63, and CK14positive myoepithelial cells, suggesting the maintenance of in vivo heterogeneity. In addition, the cultures contain subpopulations with different CD49f and EpCAM expression profiles. When grown in 3D conditions, cells self-organize into distinct structures that express either luminal or basal cell markers. Among these structures, CK8-positive cells enclosing a lumen are capable of differentiation into milk-producing cells in the presence of lactogenic stimulus. Furthermore, our short-term cultures retain the expression of ERa, as well as its ability to respond to estrogen stimulation.

Materials and Methods: We have investigated conditionally reprogrammed normal epithelial cells in terms of cell type heterogeneity, cellular marker expression, and structural arrangement in two-dimensional (2D) and three-dimensional (3D) systems.

Conclusions: The conditional reprogramming methodology allows generation of a heterogeneous culture from normal human mammary tissue in vitro. We believe that this cell culture model will provide a valuable tool to study mammary cell function and malignant transformation.

\section{INTRODUCTION}

The mature human mammary gland is a compound tubuloalveolar structure composed of milk-secreting polarized epithelial cells surrounded by myoepithelial cells, and the two-layered tissue organization is surrounded by a basement membrane [1]. During the past few decades, studying the physiology of the mammary gland in rodent models has greatly promoted our knowledge about hormone action [2], gene regulation [1, 3], and stem cell biology [4]. However, understanding the developmental process of human mammary glands 
through the knowledge gained from animal models is not ideal. The mammary glands in rodents and humans are different in several aspects such as anatomical location, histological composition, and gene expression profiles $[5,6]$. Furthermore, the whole-animal experiments make it difficult to separate and analyze molecular events at the cellular level [7]. Cultured immortalized human mammary cell lines, such as MCF-10A, have been widely used as in vitro models to study the mechanisms that dictate mammary epithelial biology. However, whether these cells serve as appropriate in vitro models for human mammary epithelial cells has recently been challenged [8]. Studies have suggested that continuous cell lines exhibit increased lineage-restricted profiles that fail to truly represent the intratumoral heterogeneity of individual breast tissues [9]. For example, normal breast cell lines demonstrate loss of

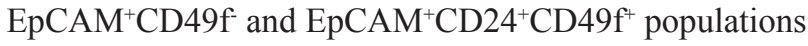
compared to primary breast epithelial cells isolated from reduction mammoplasty. Furthermore, although they retain features of bipotent progenitor cells, mammary cell lines such as MCF-10A and HME I/II are unable to differentiate into mature luminal breast epithelial cells [9]. Therefore, in vitro models that better recapitulate the physiologically relevant heterogeneity of the epithelial cells of human mammary gland tissue are desired.

Primary epithelial cells derived directly from human mammary glands provide a tissue-specific model, but comes with limitations such as a short life span in conventional tissue culture conditions [10]. A recently established method known as "conditional reprogramming" showed that irradiated fibroblast feeder cells or feeder cell-conditioned medium, together with a Rho-associated kinase (ROCK) inhibitor (Y-27632), can induce rapid and inexhaustible in vitro proliferation of primary epithelial cells from normal and malignant tissues from breast, prostate, and lung [11-14]. Moreover, the effects of ROCK inhibitor are completely reversible. Upon removal of ROCK inhibitor, conditional reprogramming cells stop proliferating and turn into terminally differentiated cells [11]. This conditional reprogramming approach has facilitated the development of patient-specific disease models such as non-small cell lung cancer (NSCLC) [15] and ductal carcinoma in situ (DCIS) [16] and paved the way for future personalized medicine. For example, forty-eight resistant NSCLC cell lines were successfully generated from tumor tissues of lung cancer patients whose disease had progressed while on treatment with epidermal growth factor receptor or anaplastic lymphoma kinase tyrosine kinase inhibitor [15]. Genetic analyses and pharmacological screening of these cell lines have identified multiple effective drug combinations that suggest potential applications for personalized medicine [15]. However, few published studies have systemically assessed the cultured normal mammary epithelial cells in terms of cell type heterogeneity, cell marker expression, and structural arrangement in three-dimensional (3D) culture. Adopting the conditional reprogramming methodology, a recent study developed an in vitro model for human DCIS from lumpectomy or mastectomy samples [16]. The established primary DCIS cultures contained both luminal and basal mammary epithelial cells and maintained tissue heterogeneity [16]. Lack of estrogen receptor- $\alpha(\mathrm{ER} \alpha)$ expression was found in primary and TERT-immortalized human mammary epithelial cells (hMECs) [17-19], as well as commonly used normal breast cell lines such as HMT3522, MCF10A, and 184B5 cells [20-22]. Similarly, ER $\alpha$ expression was lost or undetected in the in vitro culture derived from the ER $\alpha$-positive DCIS tissue [16]. Epithelial cells are known to have an inherent ability to self-organize into complex tissue structures in a 3D system [23, 24], but the study in DCIS did not show whether the conditionally reprogrammed mammary epithelial cells can form defined structures in 3D culture conditions. Another study compared the percentage of stem/progenitor/mature cells among conditionally reprogrammed epithelial cells derived from more than 60 breast specimens, however information about the ER $\alpha$ status and the 3D structure of these cultures was not reported [25].

Our long-term goal is to develop an in vitro model to study normal human mammary cell and tissue function and regulation. In working towards this goal, we exploited the conditional reprogramming method to culture primary human mammary cells from normal prophylactic tissues in both 2D and 3D culture conditions. We have demonstrated the ability of the culture to maintain heterogeneity in both luminal and myoepithelial cellular characteristics. ER $\alpha$ expression and response of primary mammary cells to estrogen stimulation were observed in short-term cultures. In addition, primary cultures spontaneously organized into distinct 3D organizations that are composed of cells expressing different epithelial markers. These results suggest that the conditionally reprogrammed cells might serve as a relevant model for the study of normal mammary cell biology.

\section{RESULTS}

\section{Morphologies of mammary epithelial cells cultured by conditional reprogramming}

Primary epithelial cells grow for a finite life span and eventually senesce $[10,26]$. Of note, those cells usually lose phenotypic heterogeneity during in vitro culture, exemplified by the gradual conversion of human mammary luminal epithelial cells to myoepithelial cells when cultured in vitro [27]. Therefore, we first investigated if epithelial cells isolated from normal human mammary tissue could be grown and expanded using the recently established conditional reprogramming method [12]. When isolated mammary gland epithelial cells from four tissue samples were plated on feeder cells, multiple colonies were formed a week later. Most colonies were composed of cells exhibiting a tightly packed cobblestone 
appearance (Figure 1A). A smaller number of colonies were composed of scattered, thin, spindle-shaped cells (Figure 1B). Even less frequently, colonies were found to comprise a mixed cell population with cobblestonelike cells in the center and spindle-shaped cells at the edge (Figure 1C). We observed none or few mammary fibroblasts in the culture, possibly because this culture condition favors the growth of epithelial cells [12]. With continuous passaging, a few cells appeared slightly enlarged compared to the cells in earlier passages, but the cultures still retained their original epithelial traits in general (data not shown), suggesting that the culture

\section{A}

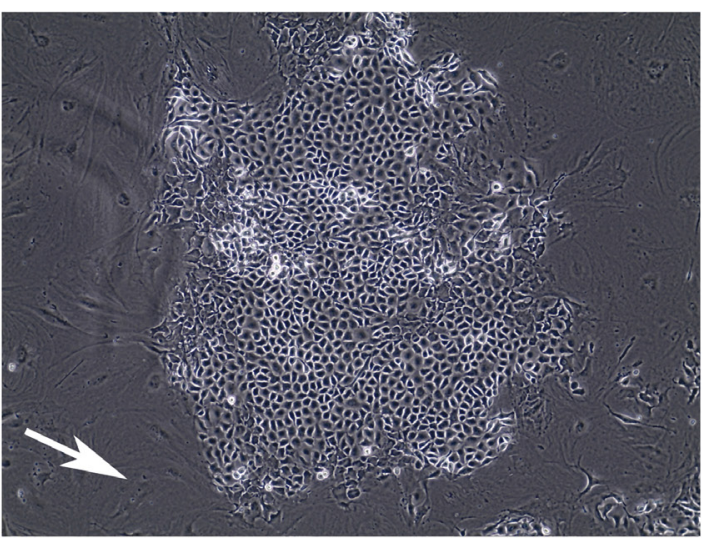

B

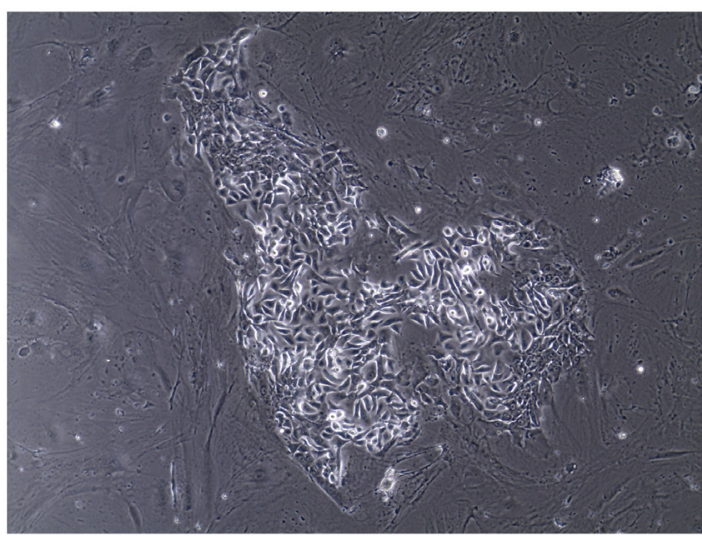

C

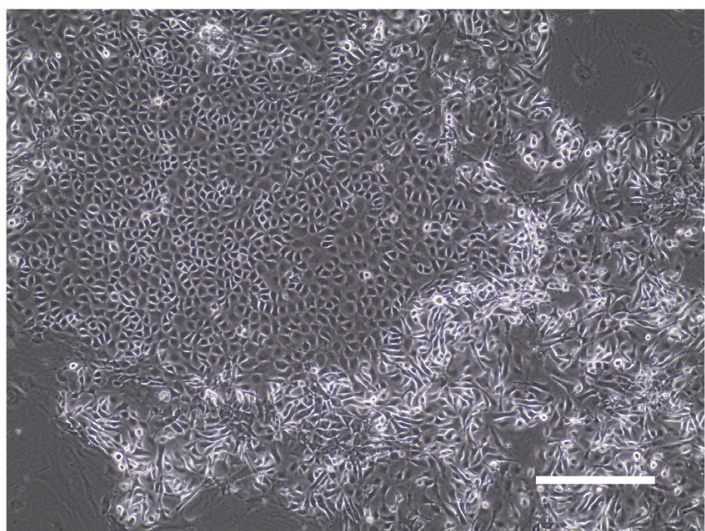

conditions preserved the cellular or morphological heterogeneity. These results demonstrate that the conditional reprogramming method allows primary mammary epithelial cells to be cultured in vitro with an extended life span.

\section{Cultured primary mammary cells express epithelial cell markers}

We next characterized the epithelial identity of cultured primary cells using immunofluorescence. As shown in Figure 2A, mammary cells were either
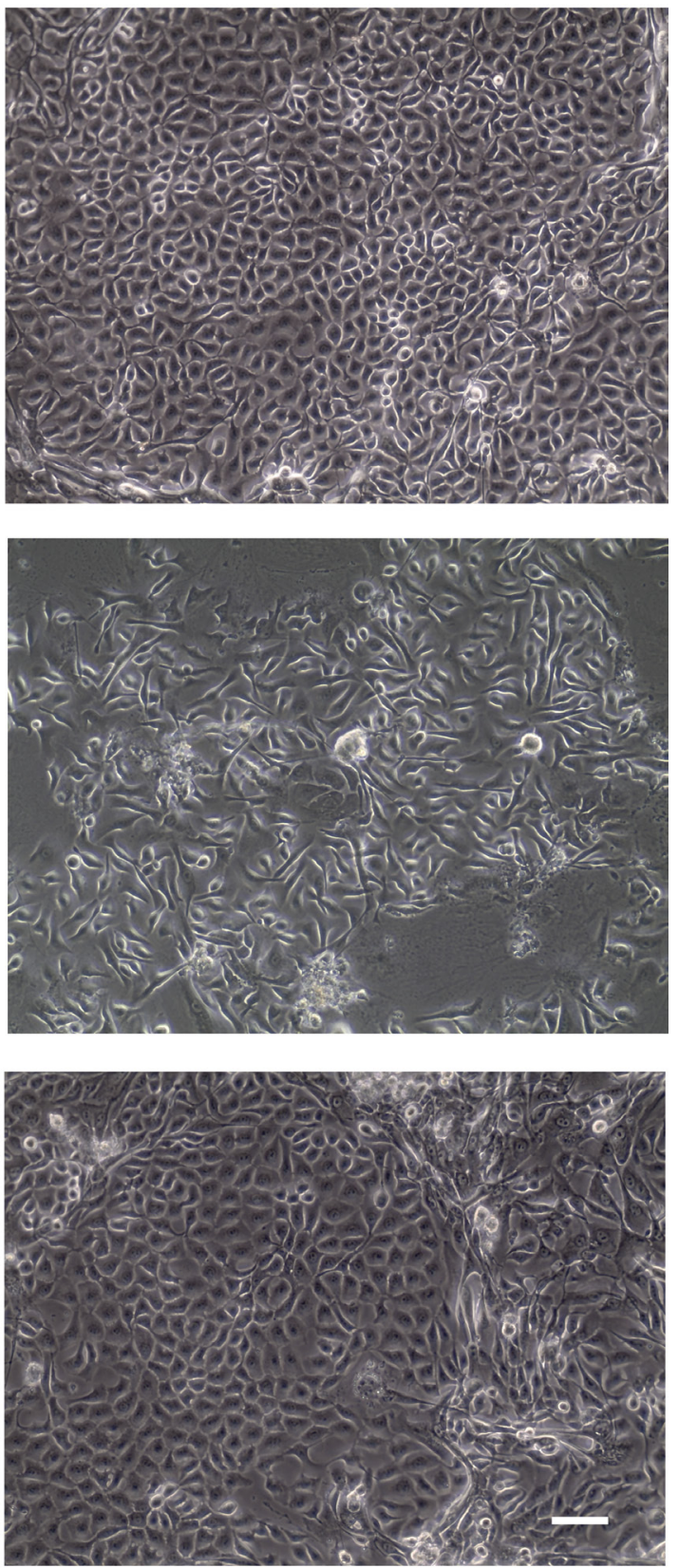

Figure 1: Colonies formed from normal human epithelial cells under conditional reprogramming condition. (A-C) Representative phase contrast pictures of colonies with various morphologies within a week of culture were shown. Feeder cells were indicated by white arrow. Bars: $200 \mu \mathrm{m}$. Original magnification: x100 (left); x200 (right). 
positive for cytokeratin 18 (CK18), a marker of luminal epithelial cells [28], or cytokeratin 14 (CK14), a marker of myoepithelial cells [29]. Notably, a few cells (arrowlabeled) were positive for both markers. Desmoglein3 is an important component of the desmosome, an intercellular junction of epithelia $[30,31]$. Its expression was only detected at the interaction surface of cobblestoneshaped epithelial cells. while expression of vimentin, a myoepithelial marker [29], was absent in these cells (Figure 2B). Conversely, desmoglein 3 was not detected in vimentin ${ }^{+}$epithelial cells (Figure 2B). CK14 and p63 are both myoepithelial markers with different subcellular locations [32]. As expected, co-staining of cytoplasmic CK14 and nuclear p63 was observed (Figure 2C).

Aldehyde dehydrogenase (ALDH) activity is commonly used to identify stem/progenitor cells [33] and this activity can be attributed to ALDH1A3 in stem cells [34]. ALDH1A3 expression was detected in a subgroup of cells and some ALDH1 A $3^{+}$cells co-expressed cytokeratin 19 (CK19) (Figure 2D). CK19 is a luminal marker [3] and loss of CK19 has been reported during in vitro culture of primary epithelial cells [35]. Interestingly, we observed evident CK19 staining in our culture and a subset of $\mathrm{CK} 19^{+}$cells harbored ALDH1A3 expression. A combination of CD49f ( $\alpha 6$ integrin) and epithelial cell adhesion molecule (EpCAM) is widely used to define cells within the luminal and myoepithelial lineages from normal human breast tissue $[9,36]$. We then carried out the flow cytometry (FACS) analysis to compare cell subpopulations with different CD49f and EpCAM expression status. As shown in Supplementary Figure $1 \mathrm{~A}$ and $1 \mathrm{~B}$, four cell populations were identified. The $\mathrm{CD} 49 \mathrm{f}+/ \mathrm{EpCAM}+$ phenotype was found to be the major fraction, followed by the CD49f+/EpCAM- and CD49f-/ EpCAM+ populations (Supplementary Table 1), which is consistent with an earlier report [25]. The heterogeneous CD49f and EpCAM expression in the total cell population was also confirmed by immunofluorescent staining (Supplementary Figure 1C).

\section{Cultured primary cells retain ER $\alpha$ expression and respond to estrogen stimulus}

Previous studies have shown consistent lack of ER $\alpha$ expression in in vitro cultures of immortalized and primary normal mammary cells [17-19, 21, 37]. Here, we tested our method to see if ER $\alpha$ expression is preserved. As shown in (Figure 3, top), strong nuclear staining of ER $\alpha$ protein was observed in a subset of cells. The test was repeated in four cultured samples with the percentage of $\mathrm{ER} \alpha^{+}$ cells ranging from $5 \%$ to $30 \%$ initially (Supplementary Table 1). The percentage of $\mathrm{ER} \alpha^{+}$cells is comparable with a previous finding that $\mathrm{ER} \alpha$ immunoreactivity was found in the nuclei of $5 \%$ to $28 \%$ of epithelial cells in acini and interlobular ducts of normal human mammary glands [38]. ER $\alpha$ signal had a moderate decrease in the early passages, and its drop was more prominent in later passages. We further performed immunoblotting analysis to confirm the expression of ER $\alpha$ in the cultures (Figure 3, bottom). In order to determine if the retained $\mathrm{ER}^{+}$cells respond to estradiol stimulation, we measured the proliferation of cultured cells when treated with estradiol relative to vehicle control (Figure 4A, left panel, white arrows) using ER $\alpha$ and Ki-67 co-staining. We observed that the percentage of $\mathrm{ER} \alpha^{+} / \mathrm{Ki}-67^{+}$was increased in the $\mathrm{ER} \alpha^{+}$pool $(P<0.01$, Figure 4B, top panel), indicating that the proliferation of $\mathrm{ER} \alpha^{+}$cells was stimulated by estradiol stimulation. This observation was also showed in $48 \mathrm{~h}$ estradiol treatment. But the percentile of $\mathrm{Ki}-67^{+}$cells in $\mathrm{ER}^{+}$population in 24-h and 48-h treatment did not show differences $(P$ $=0.58$, Figure $4 \mathrm{~B}$, bottom panel). To consolidate the study on the cell response to estradiol, we performed immunostaining of GATA3 and Ki-67 in primary cells (Figure 4A, right panel, white arrows). GATA3 is a key luminal transcription factor. It co-expresses with its direct target ER $\alpha$ and forms a positive cross-regulatory loop with ER $\alpha$ in which ER directly stimulates the transcription of the GATA3 gene [39-41]. As demonstrated in Figure 4C, we observed more $\mathrm{GATA}^{+}{ }^{+}$and $\mathrm{Ki}-67^{+} / \mathrm{GATA}^{+}$cells when the primary culture was treated with estrogen compared with vehicle control $(P<0.01)$.

\section{Primary cells organize into heterogeneous structures in 3D culture}

It has been reported that when plated into Matrigel,

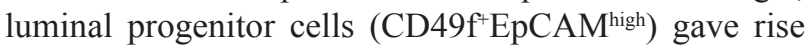
to uniformly spherical acinar structures composed of single-layer cuboidal epithelial cells expressing luminal markers [36]. In contrast, structures derived from basal

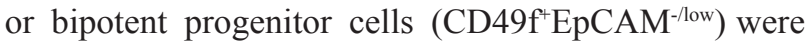
solid, irregular-shaped colonies that exhibit myoepithelial markers [36]. Thus, we explored if our primary culture comprised of luminal and myoepithelial cell populations would be able to generate distinct colonies in 3D culture. To this end, we grew the conditionally reprogrammed epithelial cells (passage 4) in Matrigel/Collagen I gel with irradiated feeder cells in fresh medium (Figure 5, left) or in feeder cell-conditioned medium only (Figure 5, right) for 2 weeks. Two types of structures formed in the mixed gel: round ductal structures with a single layer of cells enclosing a lumen and poorly organized ball-like colonies (Figure 5A, top panel). Notably, both conditioned medium and feeder cells yielded similar results that are in line with the previous finding [13]. Furthermore, immunofluorescence staining showed that the lumencontaining structure was composed of cells expressing luminal lineage markers CK18. In contrast, the ballshaped structure only consisted of cells displaying basal markers CK14 (Figure 5A, bottom panel). Consistent with this result, ER $\alpha$ staining was found in a subset of $\mathrm{CK}^{+}$cells (Figure 5B, top panel). We also detected 
A

CK18/CK14/DAPI
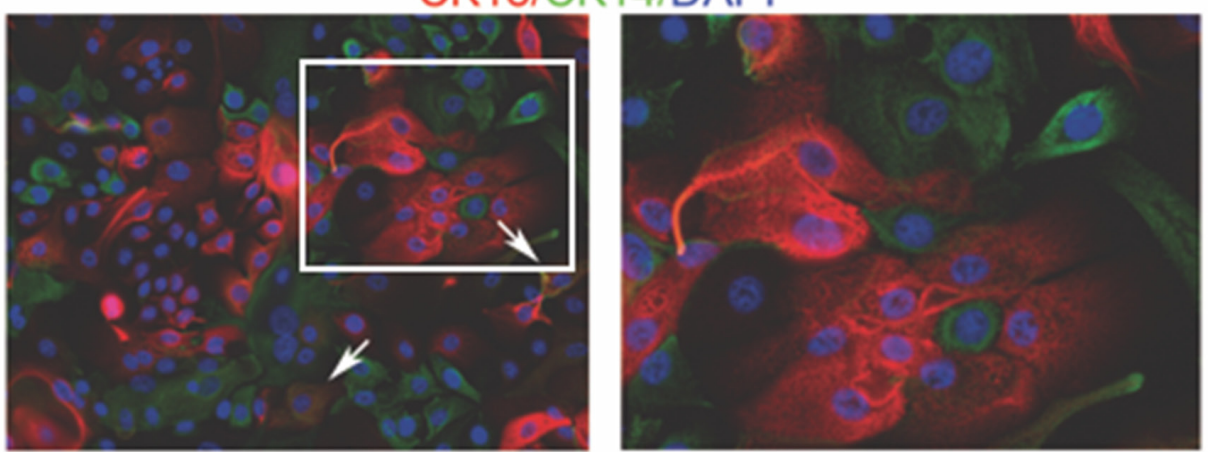

B

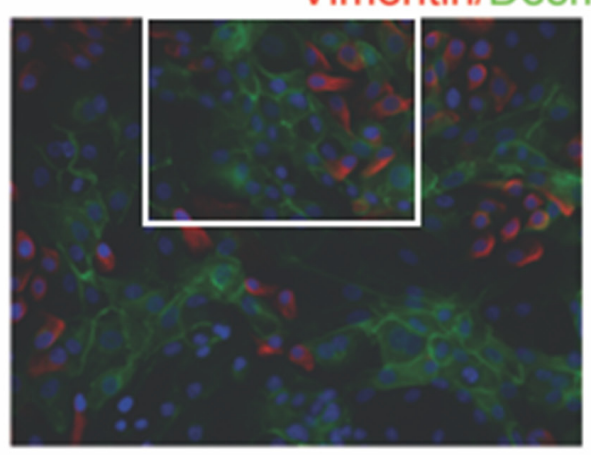

\section{Vimentin/Desmoglein3/DAPI}
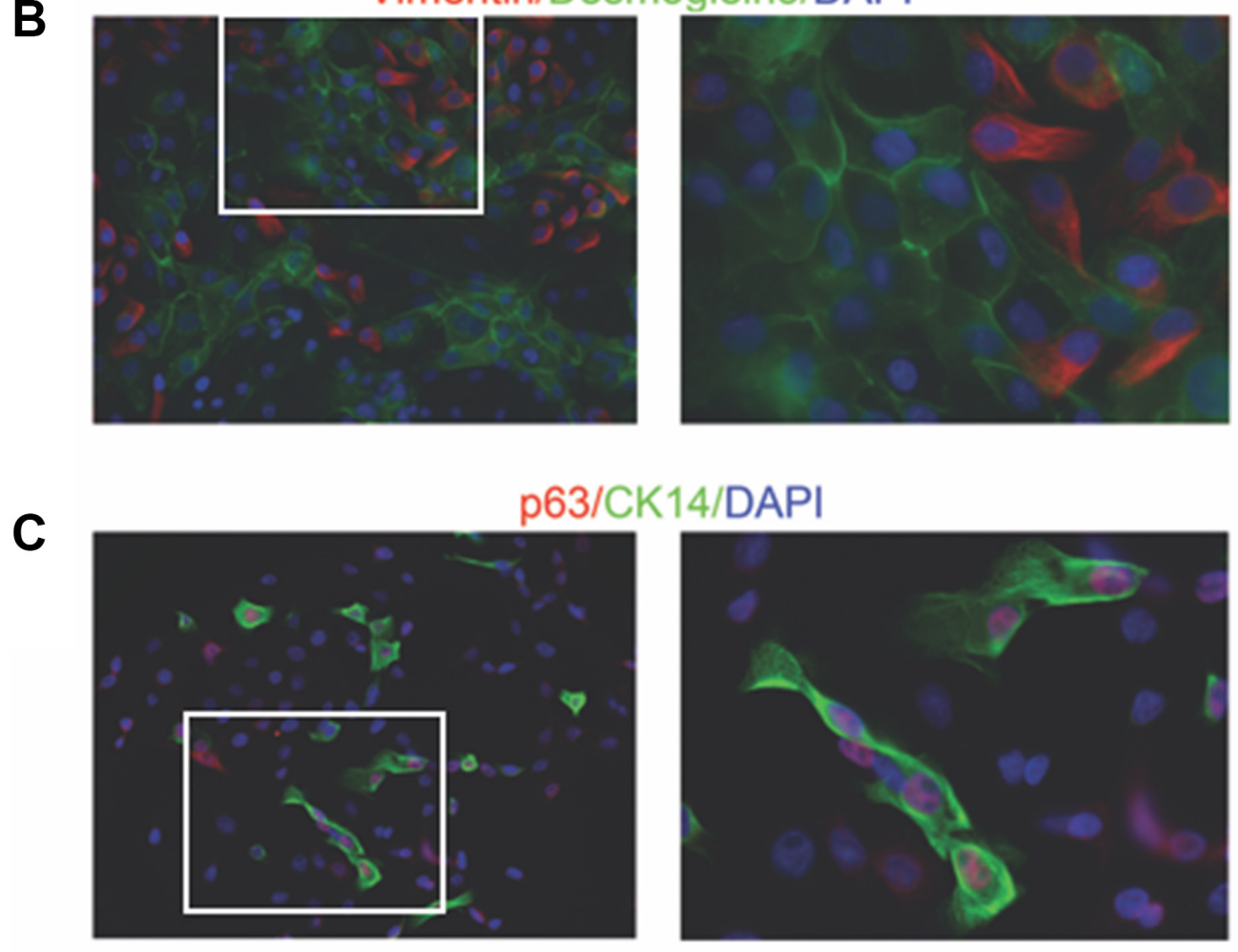

D

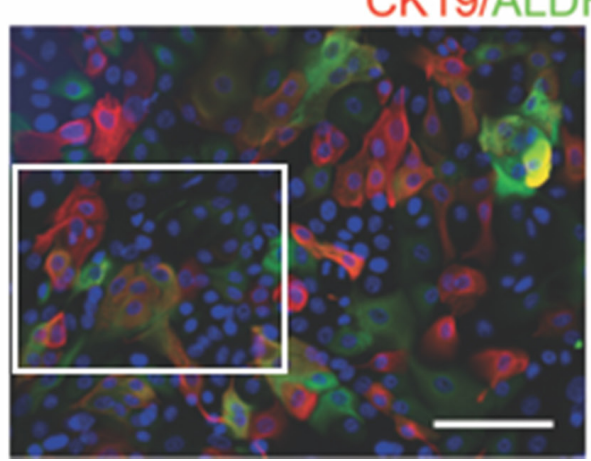

\section{CK19/ALDH1A3/DAPI}

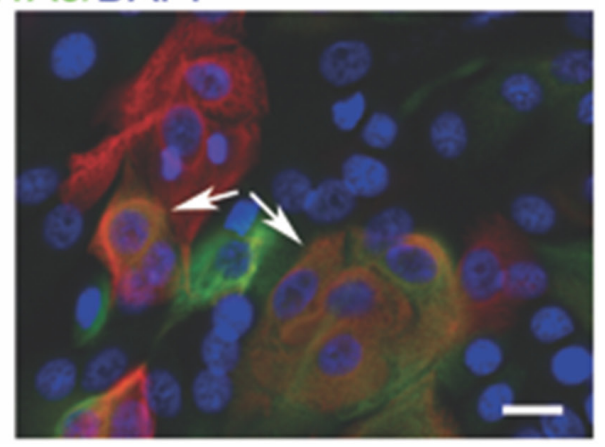

Figure 2: Immunofluorescent staining of mammary cell markers in conditional reprogrammed cells in early passage. The expression of (A-C) luminal and myoepithelial markers, (D) mature luminal and stem/progenitor cell markers was measured. All the cultures used in the immunofluorescent staining were from passage 4 (14-261). White arrows indicate the cells co-stained with two markers. The area on the left marked by the white border is shown by the magnified image on the right. Bars: $100 \mu$ m. Original magnification: $\mathrm{x} 200$ (left); x400 (right). 
strong expression of milk protein in the lumen enclosed by $\mathrm{CK}^{+}$cells (Figure 5B, bottom panel). Normal human mammary tissue was used as a positive control for milk protein staining (Supplementary Figure 2). Taken together, these data suggest that our culture maintains the ability to spontaneously organize into distinct structures.

\section{DISCUSSION}

Conditional reprogramming method has been used to expand primary epithelial cells from different normal human tissues [12]. In this study, we further investigated the characteristics of reprogrammed mammary epithelial cells and demonstrated that these cells retain many important features associated with cells from mammary tissues. The cultures contain cells expressing markers associated with luminal and myoepithelial cells. Some of the conditionally reprogrammed cells expressed both luminal and myoepithelial markers. Their cell identity is not clear. A gradual decrease in expression of CK19 during in vitro culture of primary epithelial cells has been reported as evidence of trans-differentiation from epithelial to mesenchymal phenotype [35]. The sustained CK19 staining in our culture indicates this model is able to preserve certain characteristics inherited from primary tissues within early passages. EpCAM and CD49f are widely used to define subpopulations of mammary epithelial cells. Luminal progenitors are known to exhibit a CD49f $\mathrm{f}^{+} \mathrm{ECAM}^{\text {high }}$ profile while myoepithelial cells and putative bipotent progenitor cells are defined by the CD49 $\mathrm{f}^{+} \mathrm{EpCAM}^{-/ \text {low }}$ phenotype $[9,36]$. Previous publications showed normal breast cell lines lose CD49f-EpCAM ${ }^{\text {high }}$ and $\mathrm{CD}^{-} 4 \mathrm{f}^{+} \mathrm{CD} 24^{+} \mathrm{EpCAM}^{\text {high }}$ cells. However, in our culture, we found four different subpopulations characterized by different expression levels of EpCAM and CD49f, including CD49f $\mathrm{fpCAM}^{\text {high }}$

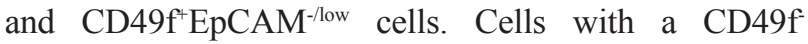
$\mathrm{EpCAM}^{\text {high }}$ profile, characteristic of mature luminal cells, were also detected. Therefore, we consider the conditional reprogramming method to retain the complex heterogeneity of mammary epithelial cells.

Under a 3D Matrigel/collagen I gel condition, we were able to obtain structures similar to those generated by $\mathrm{CD}_{49 \mathrm{f}^{+} \mathrm{EpCAM}} \mathrm{M}^{\text {high }}$ or $\mathrm{CD} 4 \mathrm{f}^{+} \mathrm{EpCAM}^{\text {-low }}$ cells, which have been considered as progenitor populations. Each structure could be formed by either the same types of progenitor cells or clumps of different progenitor cells, providing a possible explanation to the mixed structures found in a few colonies. Alternatively, those mixed structures could be generated from bipotent progenitor cells [42]. Earlier studies established mammary ductal structures from freshly isolated mammary organoids by seeding them onto hydrogel scaffolds [23] or transplanting them into mice [43]. However, these methods relied
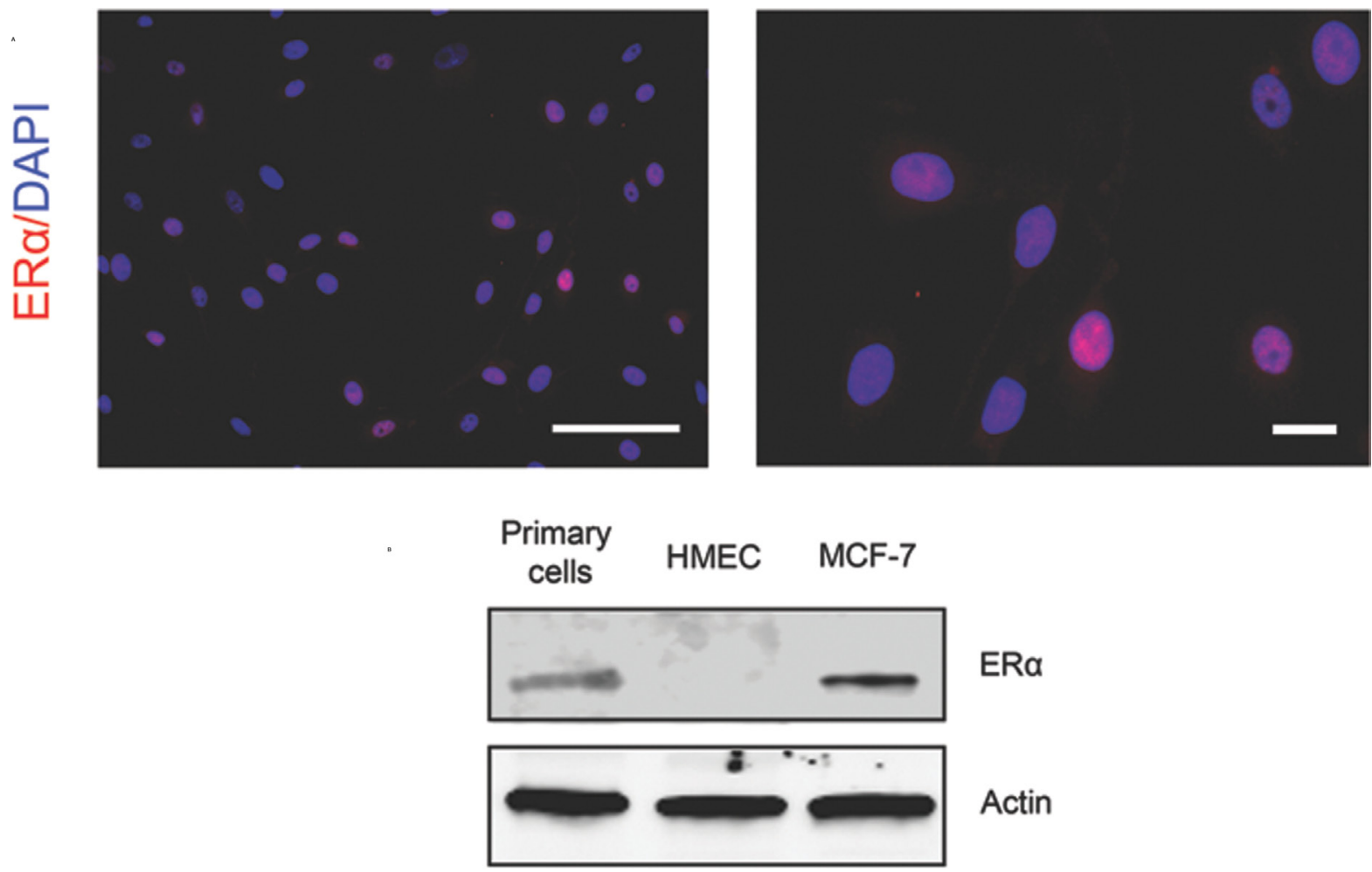

Figure 3: Expression of ER $\boldsymbol{\alpha}$ in the cultured primary mammary epithelial cells. (Top) ER $\alpha$ expression was examined by immunofluorescent staining. Secondary antibodies conjugated with AF594 (red) were used to visualize the signal. (Bottom) Western blotting analysis of ER $\alpha$ protein expression in the primary mammary epithelial cells. MCF7 and hMEC cells were used as positive and negative controls. Bars: $100 \mu \mathrm{m}$. Original magnification: x200 (left); x400 (right). 
A
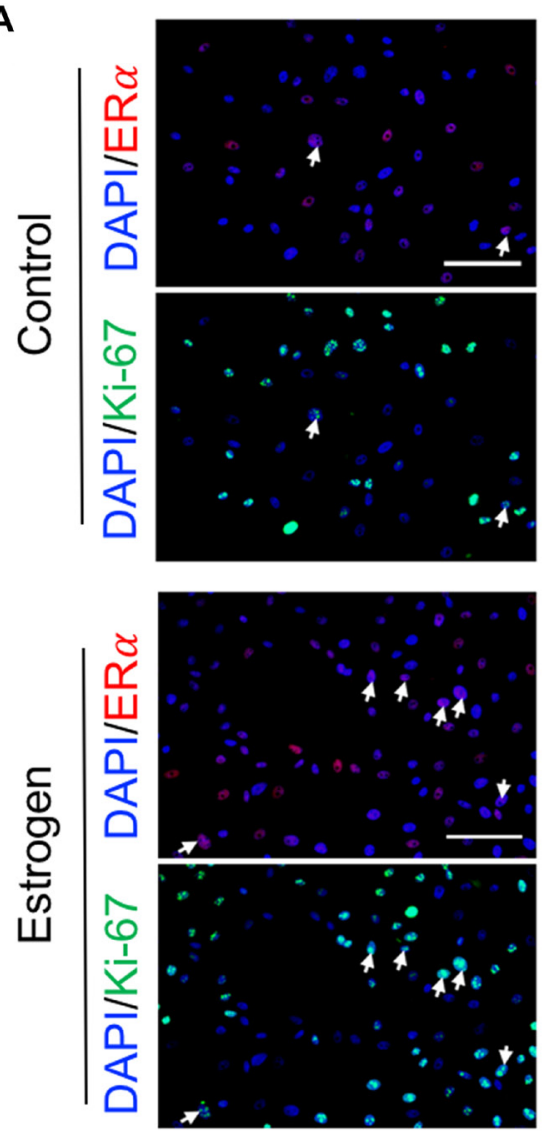

B
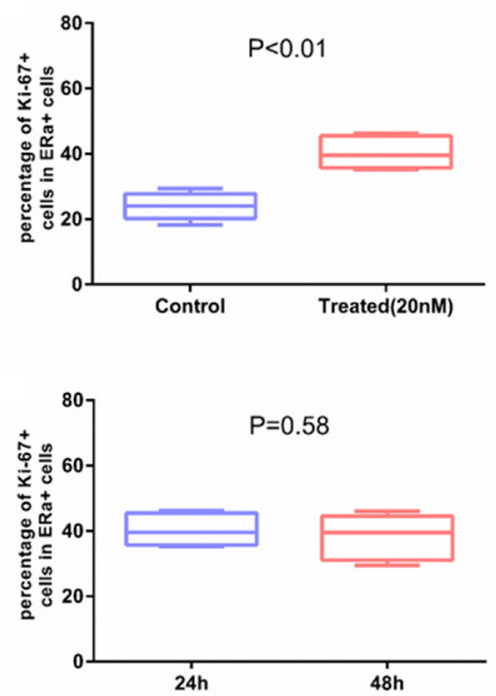
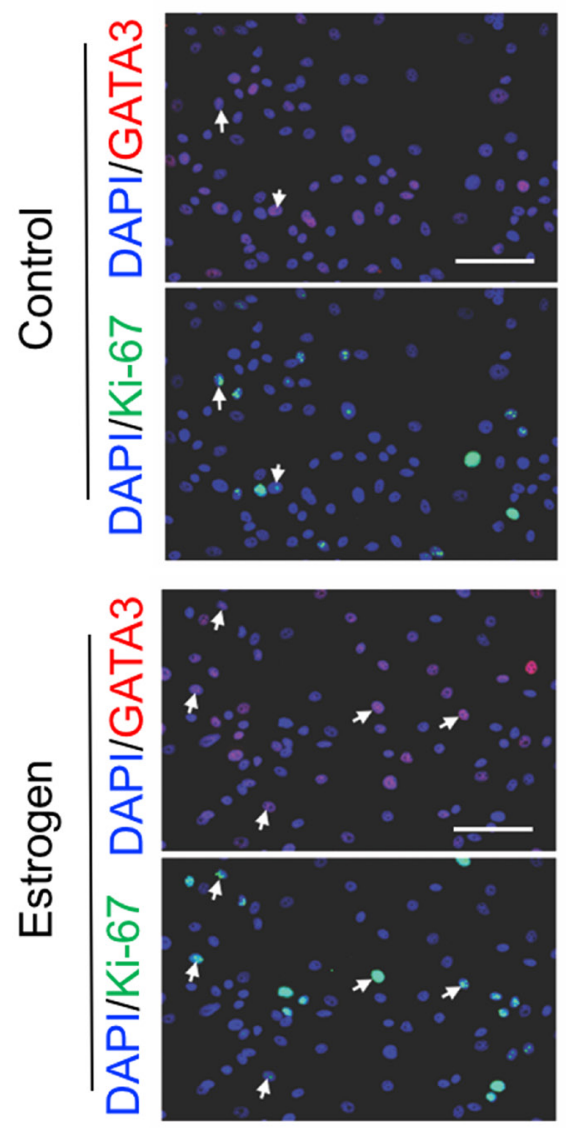

C
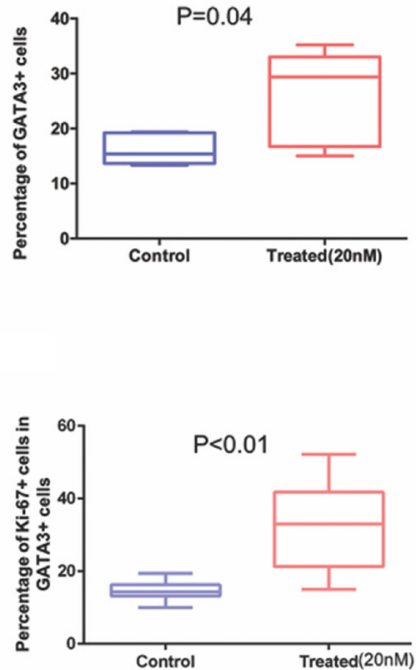

Figure 4: Proliferative response of the primary cultured mammary epithelial cells to estrogen. (A) ER $\alpha /$ GATA3 and Ki-67 expression were measured by immunofluorescence, AF594 (red) and AF488 (green)-conjugated secondary antibodies were used respectively to visualize the signals. Bottom panel: treated with estradiol, top panel: vehicle as control. The images of Ki-67 and ER $\alpha$ or GATA3 staining were taken from the same field of view. White arrows indicate proliferating ER $\alpha^{+} / \mathrm{GATA} 3$ cells. (B) Five randomly selected view fields were used to count $\mathrm{ER} \alpha^{+} / \mathrm{Ki}-67^{+}$and total $\mathrm{ER} \alpha^{+}$cells, calculated the proportion of $\mathrm{ER} \alpha^{+} \mathrm{Ki} 67^{+}$in $\mathrm{ER} \alpha^{+}$cells were plotted. Unpaired $t$ test was used to analyze the results, $P<0.01$. Cultured cells were treated with estradiol for 24 hours or 48 hours. Difference in incubated time with estradiol, the percentage of $E R \alpha^{+}$proliferating cells were analyzed, $P=0.58$. (C) Five randomly selected view fields were used to count $\mathrm{GATA}^{+} / \mathrm{Ki}^{-} 67^{+}$and total GATA3 ${ }^{+}$cells, calculated the proportion of $\mathrm{GATA}^{+}$cells after treated with estradiol or vehicle, unpaired $t$ test was used to analyze the results, $P=0.04$. Furthermore, calculated the proportion of GATA3 ${ }^{+} / \mathrm{Ki}-67^{+}$in $\mathrm{GATA}^{+}$cells were plotted and unpaired $t$ test was used to analyze the results, $P<0.01$. Bars: $100 \mu \mathrm{m}$. Original magnification: x200. 

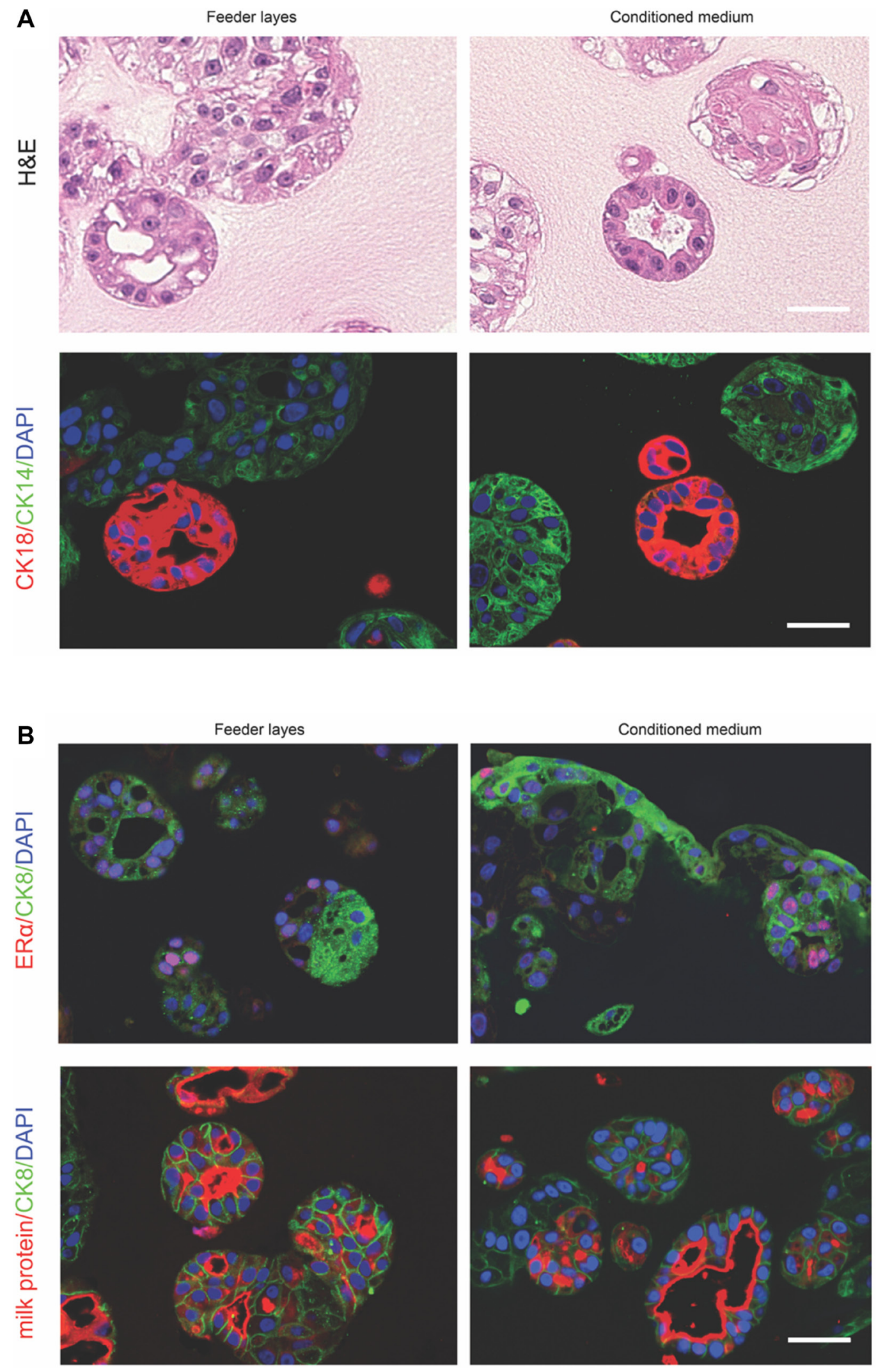

Figure 5: Conditional reprogrammed epithelial cells in 3D culture. (A, top panel), haematoxylin and eosin-stained section of the structures produced in the 3D culture. (A, bottom panel), cellular expression of CK14 and CK18. (B, top panel), ER $\alpha$ and CK8 immunofluorescence staining. (B, bottom panel), milk protein and CK8 immunofluorescence staining. Primary cells (passage 4) were cultured with feeder cells in fresh medium (left column) or in feeder cell-conditioned medium (right column). Bars: $50 \mu \mathrm{m}$. Original magnification: $\mathrm{x} 400$. 
on the original structural arrangement of different mammary cells, limiting the scope of the methods to studying regulation of cell specification, function, and differentiation. The conditional reprogramming method, on the other hand, allows in vitro propagation of epithelial cells, and preserves the progenitor-like populations and the structure-forming ability. Due to the rarity of repopulating cells among the whole epithelial cell population (about 1 per $1 \times 10^{3}$ epithelial cells), it requires at least $1 \times 10^{5}$ primary epithelial cells for the mice transplantation [43]. In contrast, conditional reprogramming does not rely on the subset of progenitor cells, but rather converts mature epithelial cells into those possessing stem-like properties and proliferating inexhaustibly in vitro, which enables expanding the culture from a very limited number of epithelial cells [12].

Previous studies have shown absence of ER $\alpha$ expression in in vitro cultures of mammary cells. For example, ER $\alpha$ expression was lost in the reprogrammed cells derived from human DCIS tissues [16]. A recent study isolated ER $\alpha+$ cells from fresh normal hMECs and tracked ER loss in these cells during culture [20]. They demonstrated that TGF $\beta$ R2 inhibitor was able to induce the restoration of ER $\alpha$ expression in cultured HMEC [20]. It is worth mentioning that we detected nuclear ER $\alpha$ staining in our 2D and 3D cultures and these $\mathrm{ER} \alpha^{+}$or $\mathrm{GATA}^{+}$cells proliferated in response to estrogen stimulation. We found that the ER $\alpha$ expression was retained in short-term culture. It is not clear whether ER $\alpha$ expression will be completely lost in later culture passages.

In conclusion, we have shown that the conditional reprogramming methodology allows in vitro generation of heterogeneous culture from normal human mammary tissue. Importantly, ER $\alpha$ expression could be detected in these cultures and estrogen activates ER $\alpha$ function. This primary culture technique supports the development of milk-producing cells and organization of distinct 3D organoid structures. This approach may provide an invaluable tool to study mammary cell function and factors involved in malignant transformation. Further studies are warranted to test whether conditionally reprogrammed cells maintain their function in vivo.

\section{MATERIALS AND METHODS}

\section{Tissue source information}

The protocol for culturing primary mammary epithelial cells was adapted from recently published methods [12-14]. This study was approved by the Institutional Review Board (IRB) at Cedars-Sinai Medical Center.

\section{Mammary epithelial cell isolation and culture}

Normal human breast tissues were obtained from prophylactic surgeries with written informed consent.
In brief, fresh mammary gland tissues were minced into $1 \mathrm{~mm}^{2}$ pieces and dissociated in collagenease and hyaluronidase mixture (Stemcell Technologies, Vancouver, $\mathrm{BC}$, Canada) overnight at $37^{\circ} \mathrm{C}$. The tissue enzyme mixture was then filtrated through a nylon strainer and the flow-through fractions were collected and centrifuged at $1200 \mathrm{rpm}$ for 10 minutes to obtain the pellets. Accumax (Innovative Cell Technologies, San Diego, CA) was used to further dissociate the organoids to obtain mostly single cells. Cells were re-suspended in F-medium. F-medium contains Dulbecco's Modification of Eagle's Medium /Ham's F-12 50/50 with L-glutamine (DMEM/ F12; 1:1) (Corning, Corning, NY), 5\% FBS, $0.4 \mu \mathrm{g} / \mathrm{mL}$ hydrocortisone, $5 \mu \mathrm{g} / \mathrm{mL}$ insulin, $8.4 \mathrm{ng} / \mathrm{mL}$ cholera toxin, $10 \mathrm{ng} / \mathrm{mL}$ epidermal growth factor (all, Sigma, St. Louis, MO), and $24 \mu \mathrm{g} / \mathrm{mL}$ adenine with addition of 10 $\mu \mathrm{M}$ Y-27632 (Enzo Life Sciences, Farmingdale, NY). The cells were then plated on a layer of $50 \%$ confluent irradiated or mitomycin-treated 3T3-J2 feeder cells for further expansion. All cultures were maintained at $37^{\circ} \mathrm{C}$ and $5 \%$ carbon dioxide. The initial colony expansion took 1-2 weeks to reach $80-90 \%$ confluence in a well of a 6-well plate and cells were split at 1:10 for later passages. Once cells reached 80-90\% confluence within 4-6 days, cells were passaged with Accutase (Innovative Cell Technologies) to avoid the harsh enzymatic condition.

\section{Immunofluorescent staining}

For 2D culture, cells were plated in 8-well chamber slides and kept in conditioned medium [13] (three volumes of feeder cell-conditioned F-medium mixed with one volume of fresh F-medium supplemented with $5 \mu \mathrm{M}$ Y-27632) to grow in a monolayer and then fixed with $4 \%$ paraformaldehyde for 15 minutes, permeabilized with $0.5 \%$ Triton X-100 for 15 minutes, and blocked with 5\% bovine serum albumin for one hour at room temperature. After blocking, cells were incubated overnight at $4{ }^{\circ} \mathrm{C}$ with primary antibodies (Supplementary Table 2). Alexa Fluor (AF) 594-(red, Molecular Probes, Eugene, OR) or AF488conjugated secondary antibody (green, Molecular Probes) were used to visualize the signal. Following three washes with PBS, slides were mounted with the VECTASHIELD mounting medium with DAPI (Vector Laboratories, Burlingame, CA). The fluorescence images were taken using the EVOS FL Auto fluorescence microscope (Life Technologies, Carlsbad, CA).

\section{Estrogen-induced proliferation assay}

Primary mammary epithelial cells (passage 3 ) were plated into 4 wells of an 8-well chamber slide with $80 \%$ confluence and cultured overnight in F-medium. Estradiol $(20 \mathrm{nM})$ was added into 2 wells and the vehicle was added to the other two wells. The cultures were incubated for 24 hours and 48 hours after Estrogen stimulation and 
then subject to fixation. Co-staining of ER $\alpha$ or GATA3 and Ki-67 were detected by immunofluorescence. Ki67, a proliferation marker [44-46], was used to analyze the proliferate ability of $\mathrm{ER}^{+}$or GATA $3^{+}$cells in our estradiolinduced proliferation assay. AF488 (green)-conjugated secondary antibody was used to visualize the Ki-67 signal, while AF594 (red) was used to visualize the ER $\alpha$ or GATA3 signal. Five randomly selected fields from each well were analyzed to calculate the proportion of $\mathrm{ER} \alpha^{+} \mathrm{Ki} 67^{+}$ cells in the total $\mathrm{ER} \alpha^{+}$pool, or calculate the proportion of $\mathrm{GATA}^{+} \mathrm{Ki}-67^{+}$cells in the total $\mathrm{GATA}^{+}$pool. An unpaired $t$ test was used to analyze the difference between the estradiol treated group and the vehicle control group.

\section{D culture}

3D "cell-embedded" culture was performed as previously reported [8, 47]. In brief, cell pellets were mixed with growth factor-reduced Matrigel (Sigma, St. Louis, MO)/collagen I (4 mg/mL, Advanced BioMatrix, Carlsbad, CA) gel (3:1 in volume) and seeded in low attachment $24-w e l l$ plates $(70 \mu \mathrm{L} /$ well, Nunclon Delta Surface plate, Thermo Fisher, Canoga Park, CA). Approximately $0.8 \times 10^{5}$ cells were seeded into each well of a 24-well plate for culture. The final concentration of collagen I in the mixed gel was $1 \mathrm{mg} / \mathrm{mL}$ [48]. In order to compare the effects of conditioned medium and feeder cells, two culture conditions were applied in the following steps: (1), the solidified gels were detached from the wells and kept floating in the conditioned medium during culture. (2), the solidified gels were detached and transferred to a different well pre-coated with feeder cells and fresh F-medium was added. For both conditions, the medium was changed every 2 to 3 days. After 2 weeks of growth, cells were fixed with $4 \%$ paraformaldehyde, washed with PBS, and embedded in Specimen Processing Gel (Histogel, American MasterTech Scientific, Lodi, CA). Samples were then processed and embedded in paraffin. Blocks were cut into 4- $\mu \mathrm{m}$ thick slides for staining. Slides were deparaffinized and rehydrated by xylene and gradient ethanol, respectively. An antigen retrieval method by microwave pretreatment and $0.01 \mathrm{M}$ sodium citrate buffer (PH6) (Vector laboratories, Burlingame, CA) was used for the following staining.

\section{Flow cytometry (FACS)}

Cells (passage 4 unless otherwise denoted) derived from four patients $(14-261,14-313,16-025,4700 \mathrm{wt}$ (passage 5)) were isolated, and approximately $2 \times 10^{5}$ cells were suspended in FACS buffer $(1 \times \mathrm{PBS}, 1 \% \mathrm{BSA})$ and incubated with antibodies at $4^{\circ} \mathrm{C}$ for 30 minutes. EpCAMFITC ( $5 \mu \mathrm{L}$ per reaction, \#347197, BD Biosciences, San Jose, CA) and CD49f ( $\alpha 6$ integrin)-AF647 (1 $\mu \mathrm{L}$ per reaction, \#562494, BD Biosciences) antibodies were used in FACS. Samples were analyzed by LSRII Flow Cytometer (BD Biosciences). Approximately 20,000 cells were collected for each sample. Data was analyzed using FlowJo Version 7.6.5 software.

\section{Immunoblotting analysis}

Total protein extraction and immunoblotting were performed using methods described previously [49]. Primary antibody against ER $\alpha$ was used to determine the level of ER $\alpha$ protein expression (Supplementary Table 1). $\beta$-actin (1:200, Santa Cruz) was used as a loading control for total protein.

\section{Abbreviations}

2D: two-dimensional; 3D: three-dimensional; ROCK: rho-associated kinase; NSCLC: non-small cell lung cancer; DCIS: ductal carcinoma in situ; ER $\alpha$ : estrogen receptor- $\alpha$; hMECs: human mammary epithelial cells; CK18: cytokeratin 18; CK14: cytokeratin 14; ALDH: Aldehyde dehydrogenase; CK19: cytokeratin 19; EpCAM: epithelial cell adhesion molecule; FACS: flow cytometry.

\section{Author contributions}

Dr. Xiaojiang Cui conceived and initiated this project. The experiments in this paper were performed by Liting Jin, Ying Qu, Liliana J Gomez, and Stacey Chung. They wrote the first draft. All the other authors contributed to the design and interpretation of the study, provided technical assistance, and helped with data analysis and manuscript preparation. Farin Amersi, Catherine Dang, and Armando E Giuliano provided fresh tissue samples and helped with biomarker characterization.

\section{ACKNOWLEDGMENTS}

This work was supported by the National Institutes of Health (CA151610), the Avon Foundation for Women (02-2014-063), and Eleanor and Glenn Padnick Discovery Fund in Cellular Therapy, to Xiaojiang Cui, the Fashion Footwear Charitable Foundation of New York, Inc., Associates for Breast and Prostate Cancer Studies, the Entertainment Industry Foundation, the Margie and Robert E. Petersen Foundation, and the Linda and Jim Lippman Research Fund to Armando Giuliano. We would also like to thank Tuantuan Zhao for the help and advice about FACS experiments.

\section{CONFLICTS OF INTEREST}

Georgetown University has been awarded a patent by the United States Patent Office $(9,279,106)$ for conditional cell reprogramming. This technology has been licensed exclusively to a new biotechnology company, Propagenix, for commercialization. Georgetown University and the inventors (X.L.) receive payments and 
potential royalties from Propagenix. The other authors declare no conflicts of interest.

\section{REFERENCES}

1. Hennighausen L, Robinson GW. Information networks in the mammary gland. Nat Rev Mol Cell Biol. 2005; 6:715725 .

2. Brisken C, O'Malley B. Hormone action in the mammary gland. Cold Spring Harb Perspect Biol. 2010; 2:a003178.

3. Clarkson RW, Wayland MT, Lee J, Freeman T, Watson CJ. Gene expression profiling of mammary gland development reveals putative roles for death receptors and immune mediators in post-lactational regression. Breast Cancer Res. 2004; 6:R92-109.

4. Van Keymeulen A, Rocha AS, Ousset M, Beck B, Bouvencourt G, Rock J, Sharma N, Dekoninck S, Blanpain C. Distinct stem cells contribute to mammary gland development and maintenance. Nature. 2011; 479:189-193.

5. Cardiff RD, Wellings SR. The comparative pathology of human and mouse mammary glands. J Mammary Gland Biol Neoplasia. 1999; 4:105-122.

6. Parmar H, Cunha GR. Epithelial-stromal interactions in the mouse and human mammary gland in vivo. Endocr Relat Cancer. 2004; 11:437-458.

7. Mroue R, Bissell MJ. Three-dimensional cultures of mouse mammary epithelial cells. Methods Mol Biol. 2013; 945:221-250.

8. Qu Y, Han B, Yu Y, Yao W, Bose S, Karlan BY, Giuliano AE, Cui X. Evaluation of MCF10A as a Reliable Model for Normal Human Mammary Epithelial Cells. PLoS One. 2015; 10:e131285.

9. Keller PJ, Lin AF, Arendt LM, Klebba I, Jones AD, Rudnick JA, DiMeo TA, Gilmore H, Jefferson DM, Graham RA, Naber SP, Schnitt S, Kuperwasser C. Mapping the cellular and molecular heterogeneity of normal and malignant breast tissues and cultured cell lines. Breast Cancer Res. 2010; 12:R87.

10. Kuilman T, Michaloglou C, Mooi WJ, Peeper DS. The essence of senescence. Genes Dev. 2010; 24:2463-2479.

11. Suprynowicz FA, Upadhyay G, Krawczyk E, Kramer SC, Hebert JD, Liu X, Yuan H, Cheluvaraju C, Clapp PW, Boucher RC Jr, Kamonjoh CM, Randell SH, Schlegel R. Conditionally reprogrammed cells represent a stem-like state of adult epithelial cells. Proc Natl Acad Sci U S A. 2012; 109:20035-20040.

12. Liu X, Ory V, Chapman S, Yuan H, Albanese C, Kallakury B, Timofeeva OA, Nealon C, Dakic A, Simic V, Haddad BR, Rhim JS, Dritschilo A, et al. ROCK inhibitor and feeder cells induce the conditional reprogramming of epithelial cells. Am J Pathol. 2012; 180:599-607.

13. Palechor-Ceron N, Suprynowicz FA, Upadhyay G, Dakic A, Minas T, Simic V, Johnson M, Albanese C, Schlegel R, Liu X. Radiation induces diffusible feeder cell factor(s) that cooperate with ROCK inhibitor to conditionally reprogram and immortalize epithelial cells. Am J Pathol. 2013; 183:1862-1870.

14. Liu X, Krawczyk E, Suprynowicz FA, Palechor-Ceron N, Yuan H, Dakic A, Simic V, Zheng YL, Sripadhan P, Chen C, Lu J, Hou TW, Choudhury S, et al. Conditional reprogramming and long-term expansion of normal and tumor cells from human biospecimens. Nat Protoc. 2017; 12:439-451.

15. Crystal AS, Shaw AT, Sequist LV, Friboulet L, Niederst MJ, Lockerman EL, Frias RL, Gainor JF, Amzallag A, Greninger P, Lee D, Kalsy A, Gomez-Caraballo M, et al. Patient-derived models of acquired resistance can identify effective drug combinations for cancer. Science. 2014; 346:1480-1486.

16. Brown DD, Dabbs DJ, Lee AV, McGuire KP, Ahrendt GM, Bhargava R, Davidson NE, Brufsky AM, Johnson RR, Oesterreich S, McAuliffe PF. Developing in vitro models of human ductal carcinoma in situ from primary tissue explants. Breast Cancer Res Treat. 2015; 153:311-321.

17. Sleeman KE, Kendrick H, Robertson D, Isacke CM, Ashworth A, Smalley MJ. Dissociation of estrogen receptor expression and in vivo stem cell activity in the mammary gland. J Cell Biol. 2007; 176:19-26.

18. Asselin-Labat ML, Shackleton M, Stingl J, Vaillant F, Forrest NC, Eaves CJ, Visvader JE, Lindeman GJ. Steroid hormone receptor status of mouse mammary stem cells. J Natl Cancer Inst. 2006; 98:1011-1014.

19. Zhao X, Malhotra GK, Lele SM, Lele MS, West WW, Eudy JD, Band H, Band V. Telomerase-immortalized human mammary stem/progenitor cells with ability to selfrenew and differentiate. Proc Natl Acad Sci U S A. 2010; 107:14146-14151.

20. Fridriksdottir AJ, Kim J, Villadsen R, Klitgaard MC, Hopkinson BM, Petersen OW, Rønnov-Jessen L. Propagation of oestrogen receptor-positive and oestrogenresponsive normal human breast cells in culture. Nat Commun. 2015; 6:8786.

21. Ronnov-Jessen L, Petersen OW, Bissell MJ. Cellular changes involved in conversion of normal to malignant breast: importance of the stromal reaction. Physiol Rev. 1996; 76:69-125.

22. Stampfer MR, Bartley JC. Induction of transformation and continuous cell lines from normal human mammary epithelial cells after exposure to benzo[a]pyrene. Proc Natl Acad Sci U S A. 1985; 82:2394-2398.

23. Sokol ES, Miller DH, Breggia A, Spencer KC, Arendt LM, Gupta PB. Growth of human breast tissues from patient cells in 3D hydrogel scaffolds. Breast Cancer Res. 2016; 18:19.

24. Sato T, Vries RG, Snippert HJ, van de Wetering M, Barker N, Stange DE, van Es JH, Abo A, Kujala P, Peters PJ, Clevers H. Single Lgr5 stem cells build crypt-villus structures in vitro without a mesenchymal niche. Nature. 2009; 459:262-265. 
25. Nakshatri H, Anjanappa M, Bhat-Nakshatri P. EthnicityDependent and -Independent Heterogeneity in Healthy Normal Breast Hierarchy Impacts Tumor Characterization. Sci Rep. 2015; 5:13526.

26. Yaswen P, Stampfer MR. Molecular changes accompanying senescence and immortalization of cultured human mammary epithelial cells. Int J Biochem Cell Biol. 2002; 34:1382-1394.

27. Pechoux C, Gudjonsson T, Ronnov-Jessen L, Bissell MJ, Petersen OW. Human mammary luminal epithelial cells contain progenitors to myoepithelial cells. Dev Biol. 1999; 206:88-99.

28. Putti TC, El-Rehim DM, Rakha EA, Paish CE, Lee $\mathrm{AH}$, Pinder SE, Ellis IO. Estrogen receptor-negative breast carcinomas: a review of morphology and immunophenotypical analysis. Mod Pathol. 2005; 18:2635 .

29. Sousa B, Paredes J, Milanezi F, Lopes N, Martins D, Dufloth R, Vieira D, Albergaria A, Veronese L, Carneiro V, Carvalho S, Costa JL, Zeferino L, et al. P-cadherin, vimentin and CK14 for identification of basal-like phenotype in breast carcinomas: an immunohistochemical study. Histol Histopathol. 2010; 25:963-974.

30. Garrod D, Chidgey M. Desmosome structure, composition and function. Biochim Biophys Acta. 2008; 1778: 572-587.

31. Runswick SK, O'Hare MJ, Jones L, Streuli CH, Garrod DR. Desmosomal adhesion regulates epithelial morphogenesis and cell positioning. Nat Cell Biol. 2001; 3: 823-830.

32. Batistatou A, Stefanou D, Arkoumani E, Agnantis NJ. The usefulness of p63 as a marker of breast myoepithelial cells. In Vivo. 2003; 17:573-576.

33. Ginestier C, Hur MH, Charafe-Jauffret E, Monville F, Dutcher J, Brown M, Jacquemier J, Viens P, Kleer CG, Liu S, Schott A, Hayes D, Birnbaum D, et al. ALDH1 is a marker of normal and malignant human mammary stem cells and a predictor of poor clinical outcome. Cell Stem Cell. 2007; 1:555-567.

34. Sarrio D, Franklin CK, Mackay A, Reis-Filho JS, Isacke CM. Epithelial and mesenchymal subpopulations within normal basal breast cell lines exhibit distinct stem cell/ progenitor properties. Stem Cells. 2012; 30:292-303.

35. Taylor-Papadimitriou J, Stampfer M, Bartek J, Lewis A, Boshell M, Lane EB, Leigh IM. Keratin expression in human mammary epithelial cells cultured from normal and malignant tissue: relation to in vivo phenotypes and influence of medium. J Cell Sci. 1989; 94:403-413.

36. Lim E, Vaillant F, Wu D, Forrest NC, Pal B, Hart AH, Asselin-Labat ML, Gyorki DE, Ward T, Partanen A, Feleppa F, Huschtscha LI, Thorne HJ, et al. Aberrant luminal progenitors as the candidate target population for basal tumor development in BRCA1 mutation carriers. Nat Med. 2009; 15:907-913.

37. Novaro V, Roskelley CD, Bissell MJ. Collagen-IV and laminin-1 regulate estrogen receptor alpha expression and function in mouse mammary epithelial cells. J Cell Sci. 2003; 116:2975-2986.

38. Li S, Han B, Liu G, Li S, Ouellet J, Labrie F, Pelletier G. Immunocytochemical localization of sex steroid hormone receptors in normal human mammary gland. J Histochem Cytochem. 2010; 58:509-515.

39. Eeckhoute J, Keeton EK, Lupien M, Krum SA, Carroll JS, Brown M. Positive cross-regulatory loop ties GATA-3 to estrogen receptor alpha expression in breast cancer. Cancer Res. 2007; 67:6477-6483.

40. Asselin-Labat ML, Sutherland KD, Barker H, Thomas R, Shackleton M, Forrest NC, Hartley L, Robb L, Grosveld FG, van der Wees J, Lindeman GJ, Visvader JE. Gata-3 is an essential regulator of mammary-gland morphogenesis and luminal-cell differentiation. Nat Cell Biol. 2007; 9:201209.

41. Kouros-Mehr H, Slorach EM, Sternlicht MD, Werb Z. GATA-3 maintains the differentiation of the luminal cell fate in the mammary gland. Cell. 2006; 127:1041-1055.

42. Stingl J, Eaves CJ, Zandieh I, Emerman JT. Characterization of bipotent mammary epithelial progenitor cells in normal adult human breast tissue. Breast Cancer Res Treat. 2001; 67:93-109.

43. Eirew P, Stingl J, Raouf A, Turashvili G, Aparicio S, Emerman JT, Eaves CJ. A method for quantifying normal human mammary epithelial stem cells with in vivo regenerative ability. Nat Med. 2008; 14:1384-1389.

44. Gerdes J, Lemke H, Baisch H, Wacker HH, Schwab U, Stein H. Cell cycle analysis of a cell proliferation-associated human nuclear antigen defined by the monoclonal antibody Ki-67. J Immunol. 1984; 133:1710-1715.

45. Gerdes J. Ki-67 and other proliferation markers useful for immunohistological diagnostic and prognostic evaluations in human malignancies. Semin Cancer Biol. 1990; 1:199206.

46. Kill IR. Localisation of the Ki-67 antigen within the nucleolus. Evidence for a fibrillarin-deficient region of the dense fibrillar component. J Cell Sci. 1996; 109:1253-1263.

47. Lee GY, Kenny PA, Lee EH, Bissell MJ. Three-dimensional culture models of normal and malignant breast epithelial cells. Nat Methods. 2007; 4:359-365.

48. Krause S, Jondeau-Cabaton A, Dhimolea E, Soto AM, Sonnenschein C, Maffini MV. Dual regulation of breast tubulogenesis using extracellular matrix composition and stromal cells. Tissue Eng Part A. 2012; 18:520-532.

49. Jin Y, Han B, Chen J, Wiedemeyer R, Orsulic S, Bose S, Zhang X, Karlan BY, Giuliano AE, Cui Y, Cui X. FOXC1 is a critical mediator of EGFR function in human basal-like breast cancer. Ann Surg Oncol. 2014; 21:S758-766. 